
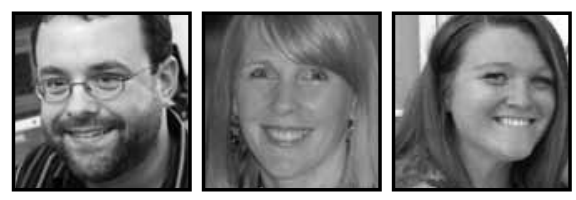

\title{
Reimagining a Writer's Process Through Digital Storytelling
}

\author{
Troy Hicks, Central Michigan University \\ Kristen Turner, Fordham University \\ Jodi Stratton, Central Michigan University
}

\section{ABSTRACT}

Building on Hillocks' (1995) concepts of the declarative and procedural knowledge that writers need in order to craft effective writing, this article explores the writing process of one pre-service teacher as she moved from a personal narrative to an essay to a digital story. The authors argue that digital writers-in addition to needing declarative and procedural knowledge-must also understand knowledge of technology in order to more fully realize the potential of digital storytelling. Implications for teachers and teacher educators are discussed in relation to Mishra and Koehler's (2008) "technological pedagogical content knowledge," or TPACK.

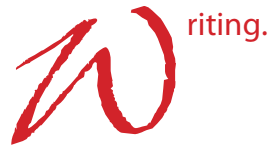

It is one of the three " $\mathrm{R}$ 's" of education.

It is central to our lives as humans.

It continues to change as our world becomes increasingly digital.

And it is incredibly difficult to teach. 
As with many subjects, teachers can be excellent writers, yet not have the pedagogical knowledge to teach others how to write well. Similarly, teachers may understand how to engage students in the writing process and have conversations about traits of writing, yet not have the deep knowledge and set of skills as writers themselves to share with their students. These challenges are compounded in a digital world. Writing is no longer simply an act of putting pen to paper; writers must navigate tools of technology that may support or constrain their ability to communicate a message. Given this ever-shifting landscape of what it means to write and be a teacher of writing, many teachers enter classrooms without developing their skills as writers, and even fewer as digital writers who compose websites, slide shows, or other forms of multimedia. As teacher educators and National Writing Project participants, we (Troy and Kristen) understand that teachers must be writers themselves (Lieberman \& Wood, 2003; National Writing Project \& Nagin, 2006). We must help the teachers with whom we work to develop their own knowledge, even as they consider how to help their students grow as writers. And, as we have considered the nature of knowledge that writers need in a digital world, we have shifted our teaching to include both traditional writing assignments such as personal narratives and argumentative essays, as well as digital writing pieces. Defined by the National Writing Project, DeVoss, Eidman-Aadahl, \& Hicks (2010) as a "compositions created with, and oftentimes for, reading and/or viewing via a computer or other device that is connected to the Internet" (p. 7, emphasis in original), digital writing can include a wide variety of tools such as blogs, wikis, collaborative word processors, shared notebooks, and, as described in this article, digital storytelling. We want our students to develop their knowledge of writing in a digital world. We want them to practice writing digitally. We want them to think critically about how digital writing opens possibilities for exploration of self and other.

As teacher educators, we reflect upon these goals with the help of someone who knows this process well, Jodi, a pre-service teacher who developed her writing in Troy's class, "Writing in the Elementary and Middle Schools." In the fall of 2012, Jodi developed a number of writing pieces including a writer's profile, a personal narrative, and a "This I Believe" essay that focused on the broad idea of "social change," a theme inspired by her involvement with Alternative Breaks, a program at the university that sponsored meaningful volunteer work during academic breaks. Troy believed that by having his students engage as writers, they would better understand their processes, as well as the elements of this kind of personal essay writing. Later in the semester, Troy asked pre-service teachers to build upon this knowledge by creating digital stories that further explored a topic of personal significance. As defined by author and educational consultant Bernajean Porter, 
Digital Storytelling takes the ancient art of oral storytelling and engages a palette of technical tools to weave personal tales using images, graphics, music and sound mixed together with the author's own story voice. Digital storytelling is an emerging art form of personal, heartful expression that enables individuals and communities to reclaim their personal cultures while exploring their artistic creativity. While the heart and power of the digital story is shaping a personal digital story about self, family, ideas, or experiences, the technology tools also invite writers and artists to think and invent new types of communication outside the realm of traditional linear narratives. (Porter, n.d.)

Thus, the digital story project provided an opportunity for Jodi to express herself as a writer and to think critically about how to integrate technology into her own teaching. Jodi immediately connected the digital assignment to her "This I Believe" essay, recognizing that the digital mode may allow her to accomplish more by connecting deeply with her audience; she was unsure how to execute her plan.

Like all writers who are learning and changing as they build larger vocabularies, experience more in life, and gain a more sophisticated set of rhetorical skills, Jodi needed to add a layer to her knowledge. She needed to understand how the tools of technology could help her tell the story and how the form of a digital story could broaden the focus of her personal essay. Through her work with Troy, Jodi was able to develop her procedural, declarative, and technological knowledge to accomplish her writing goals, and we will elaborate on these forms of knowledge below. In particular, Jodi took the initiative to schedule a writing conference with Troy on the Friday before the digital story was due. Part of the talking and thinking that went on in that conversation was, fortunately, captured in some notes that Troy took while Jodi described her vision for the digital story and discussed how she might use the ideas from her "This I Believe" essay that could translate into a digital story.

Through the rest of this article, the three of us have worked collaboratively to provide a framework for thinking about Troy's decisions as a writing teacher and teacher educator, as well as Jodi's decisions as a digital writer. We begin by adapting Hillocks' framework of declarative and procedural knowledge that writers need and expanding that framework to include a third dimension that includes digital writing. Then, we share Jodi's reflections on the process of composing her digital story. Finally, we close with a discussion of how digital writing both expands and complicates the decisions that writers and teachers of writing must make as we incorporate newer literacies and technologies into our teaching and learning. 


\section{The Knowledge Writers Need}

Hillocks (1995) articulated a sociocultural view of writing that evolves from a rich history of composition theory. He suggested that traditional writing instruction focuses on declarative knowledge-telling students what a given genre should look like or include-and he argued that "the important knowledge is procedural" (p. 99), or how to produce the writing itself.

Hillocks described the difference in this way:

It is one thing to identify the characteristics of a piece of writing but quite another to produce an example of the type.... Knowledge of discourse, then, appears to have two dimensions: declarative knowledge, which enables identification of characteristics, and procedural knowledge, which enables production. (p. 121)

Perhaps a more blunt way to put his findings would be this: it's relatively easy for students to tell us about the qualities of good writing. That is, they generally know what good writing looks like. However, knowing how to craft good writing is much more difficult. In fact, Hillocks argued further that writers need knowledge of discourse (the form of the writing) and knowledge of substance (the content of the writing). Smith and Wilhelm (2006) conceptualized this knowledge in a table, aligning declarative and procedural knowledge of writing with the form and substance of that writing into a blank table, showing the relationship between these ideas (p. 124). We have adapted their table into Figure 1, elaborating on the intersections of these ideas.

FORM

What the writing itself is, including the generic/conventional characteristics

\section{SUBSTANCE}

Declarative Knowledge (Answers the question "what"?; can be tested.)

Procedural Knowledge (Answers the question "how"?; must be produced.)
How to generate the needed characteristics
The content, topic or subject of the writing

How to generate the content (inquiry)

Fig. 1: An elaboration on Smith and Wilhelm's interpretation of Hillocks' declarative and procedural knowledge 
For Smith and Wilhelm, then, using procedural knowledge is putting "declarative knowledge into practice" (p. 125). This framework suggests that writers need a knowledge of what, which includes identifying the characteristics of the genre and the content focus of the writing, as well as the knowledge of how to produce the writing in a way that effectively communicates the message.

Examining Jodi's path through Troy's class, we can see her expertise as a writer grow. In Figure 2, Jodi's final draft of the personal narrative, which was due about one-third of the way into the semester, is presented and, in Figure 3, Jodi's final draft of the "This I Believe" essay, due about two-thirds of the way through the semester, is shared. Both are worth reading, as they demonstrate Jodi's competence as a writer. As a future teacher of English who herself was an advanced writer, she possessed the declarative and procedural knowledge of form to write a personal narrative in the form of this essay. She knew how to focus on a main theme and to add appropriate detail to craft the essay. She was able to tap into her experience as a participant in Alternative Breaks to generate the content for that piece, focusing broadly on the idea of "social change." She successfully met the goals of the assignment and her personal goals as a writer, and she earned positive responses from her classmates, especially on the final line of her essay: "For this, I believe in social change."

It took a lot of effort to get me in the van the day the trip left. I was feeling a whirlwind of emotions that I couldn't process. I didn't want to have a life changing experience anymore, I wanted to stay the same for the rest of my life.

I was a sophomore who hadn't quite realized that what I needed the most was a little growth; strike that - a lot of growth -- and a life changing experience.'s It would set up the foundation for the rest of my college career and now, my life. The world was mine, people were just living in it. I had a great boyfriend, lots of friends, was beginning to get involved at CMU and felt on top of the world. My RA approached me about doing something called an Alternative Break. He was just doing PR for the program and really trying to get as many people to sign up as they possibly could. I looked into what issues they offered for summer breaks and I was immediately enticed by the name Education printed on the screen. I called my mom and told her I was going to sign up for this Alternative Break thing and see what it was all about. She didn't think there was anything that sounded too harmful about a group of $12 \mathrm{CMU}$ students going to a set location for the week and offering service in a local elementary school. When I put my name on the list for going to the break I was so excited yet I had nerves rushing through me because I had no idea what was in store for me. My friend also got the same break I did and he had been on several $\mathrm{ABs}$ before, in fact he was on the $\mathrm{AB}$ Advisory Board. But he didn't want to reveal the location we were going or answer too many questions about the break so that I could get the full experience that most $\mathrm{ABers}$ get.

My first meeting came around and I left feeling indifferent, the trip was in Reno Nevada and we would be there for a whole week. How was I going to make it 40 hours in a car and drive all the way across the nation? My family felt the same hesitations that I did because this was such a new experience for us all. We had no idea how we were getting from point $A$ to point $B$, what the cost was going to be and what we would do for food. As the meetings went by I was getting more and more questions answered and I began feeling really prepared about going and doing this service. 
Looking back on this now, the sequence of events that led up to this experience are a blur. Within, the span of a month, I had lost the most important people to me at CMU. My boyfriend broke up with me, my friends were slipping away and my involvements were all coming to a close due to the school year ending. I didn't know what I was going to do, I was going on an Alternative Break to volunteer and just to focus on that.

It took a lot of effort to get me in the van the day the trip left. First off, it was Four o'clock in the morning and I felt such a variety of emotions that my body was basically numb. I had to drive a van with five other passengers and I was not prepared of that, when they asked me to drive first, my stomach felt like it fell out of my butt. I got in the driver's seat and followed the lead van. I didn't have time to think about anything else but making sure everyone else was safe and that my driving wasn't terrible. Hours went by and I was still driving, I was beginning to grow tired but didn't want to let anyone know that I needed to stop. Eventually, we stopped and decided to switch drivers. The whole rest of the trip I was very quiet, unless my friend Robert was talking to me and trying to engage me in the conversation of the other participants in the van. I spent a lot of time on my phone, texting my mom and my friend Steve who was in the van in front of us.

The drive seemed to take forever but we arrived at our halfway point, Wellington Colorado. We got there when it was dark and slept for about 6 hours.As we got into the vans the next morning, I remember the smell of the fresh altitudy air in my nostrels and thinking how I felt so at peace. We got in the vans and continued the drive through the rolling hills and mountains of Colorado, Utah and Nevada. The change of scenery happened so quickly it was like someone had dropped tall buildings and lights in front of the mountains.

We got settled into our housing for the week and decided that we would explore the Biggest Little City in the World, Reno NV. It was unlike anything I had ever seen. We went to the top of a parking garage and I looked to my right, I could see snow capped mountains, and to my left, buildings and lots of lights. It was like a mini Las Vegas.

The next morning came around and I was going to my Kindergarten classroom for the first time, alone. What do I do? Will the kids be different from my class at home? Do I have the skills to be effective? What do I say? I felt lost. I walked in the classroom and was welcome with open arms by my teacher and the students. They had so many questions to ask me. From my favorite color to are you married, I was beginning to feel more at ease as the day went on.Each night we did a reflection that taught me more about who I was and what I stood for as an individual. It didn't matter if my opinion was different from someone else's. It only mattered that I respected the opinions of others and kept an open mind. As the week progressed its hard to describe my growth, I couldn't see it physically but I could feel it. I felt like for the first time in my life that Reno Nevada was a city made just for me.

To this day, I still struggle with finding the right words to describe the growth that I have experienced not only on this break but on the six break that I have been on. I can only allow my actions to speak louder than my words and hopefully my actions can one day become words.

Fig. 2: Jodi's personal narrative 
Like the wind, change is something you feel, not something that can be seen. Change can happen in large quantities or through small acts of kindness. Cesar Chavez said "once social change begins, it cannot be reversed You cannot uneducate the person who has learned to read. You cannot humiliate the person who feels pride. You cannot oppress the people who are not afraid anymore. We have seen the future, and the future is ours." For this, I believe in social change.

Reflecting on my college career, it's hard to remember what my life was like before my first alternative break. I hardly have a single memory that doesn't include my time or the friends I have made through this program, whether it be as a participant, a site leader or a board member.

As a 19 year old participant with big dreams and under developed thoughts about the world, I thought that social change would be something easy, tangible and that everyone would quickly agree to. As a site leader, I saw the hope and sparkle in the eyes of my peers that turned this concept of social change, into something that could become a movement. Now, as a board member, I plan to incorporate social change in my classroom (as a teacher and a professor) and into my everyday life.

Through CMU Alternative Breaks, I have had the opportunity to develop into a life-long active citizen in local, national and global communities through diverse, direct-service experiences dedicated to social justice. To bring to life an example of a time when this statement has proven itself true is not an easy task yet it is one, much like my battle with social change, that I would be compelled to describing.

What the Alternative Breaks program has encompassed me with is not only a love for service, but also a realistic ability on how change can be made through small acts of random kindness. that the world has the ability to change us as people, but also that a small group of dedicated individuals have the ability to change the world. Like Chavez said, once social change begins it cannot be reversed, and my transformation as a leader is irreversible. For this, I believe in social change.

Fig. 3: Jodi's "This I believe" essay

As the semester moved forward, Troy shifted expectations, taking Jodi (and many of her classmates) out of her comfort zone as a writer by introducing concepts related to digital writing. In particular, he introduced the idea of digital storytelling, a genre in which digital writers combine a narrated script, images, transitions, video effects, and music to create short movies. Since the 1990s, when programs such as Windows Movie Maker and iMovie have come packaged on personal computers, the possibilities for creating digital stories have continued to expand. And, as one of many genres that he could ask students to produce as a final project in this methods course, Troy felt that digital stories offered a good way to synthesize students' learning from the semester.

After sharing two examples of digital stories, Troy introduced basic techniques for crafting such a text. These lessons focused both on declarative and procedural knowledge and included elements such as creating a timeline, including transitions, and recording narration. Still, even after writing about her experience in the 
Alternative Breaks program earlier in the semester, when Jodi first tackled writing her digital story, she faltered. Like many students in the class, she had difficulty in capturing her ideas in text-based writing while preparing the digital timeline for the video components of the story. At her request, she scheduled a meeting during office hours with Troy, a conference she did not need to fulfill a requirement for the course, but chose to take on so that she could learn how to craft an effective digital story that she would want to share with her friends and family.

\section{The Knowledge Digital Writers Need}

Perhaps the reason Jodi needed additional support in the writing of this digital piece, one that built from the same personal experience as the text-based narrative she had written earlier, is that the framework laid out by Hillocks (1995) becomes more complicated when looking at digital genres. A digital story is a composition that involves spoken words, images, video, and other multimedia effects. Unlike its cousin, the personal narrative, the digital story provides writers with a broad palette of tools of technology that support rhetorical choices. In short, crafting a digital story requires technological knowledge, in addition to declarative and procedural knowledge.

So what knowledge does a writer need to create an effective digital story? As in the personal narrative, Jodi needed to understand first the elements of narrative (e.g., character, conflict, dialogue), but she also needed knowledge of images/ video, music/sound effects, and transitions/captions/video effects. She needed to know that digital stories employee these techniques, but she also needed to know how to use them effectively to move her story forward and to capture the audience. Furthermore, she needed to understand the affordances of the technology both from the perspective of the genre (form) and the content of the story itself (substance).

Porter (in Hicks, 2009) has suggested that media can be used in three levels in digital storytelling. In her view, media might (1) decorate the story, (2) illustrate the story, or (3) illuminate the story. Decorating is easy; finding clip art or an image from the Internet will do, and matching it up with the script being read is sufficient. Illustrating takes a bit more work, in the sense that the digital writer may use her own images or create new ones, using them to highlight the spoken words. In order for media to "illuminate" the story, a writer needs knowledge of technology and how it intersects with both the form and the substance of the writing. The words, images, 
transitions, and sounds work together so that the "whole" of the digital story is truly more than just the sum of its parts.

Visually, we have enhanced Smith and Wilhelm's table by making it into a cube when thinking about digital genres, where the front of the cube encompasses what we know about traditional, print-based forms of writing and moving deeper into the cube generatively complicates what we know and leads us to (potentially) richer forms of digital writing. In this model, writers need to know both the "surface" level of declarative and procedural knowledge as well as the "depth" that they can add with technologies for digital writing (See Figure 4). As a concrete example, it is the difference between knowing how to describe a character in writing as compared to using an image to introduce a character and, with just enough writing, describe her in a way that illustrates or illuminates her picture. In this way, the introduction of technological knowledge intersects with both form and substance, complicating the one-dimensional grid of writer knowledge.

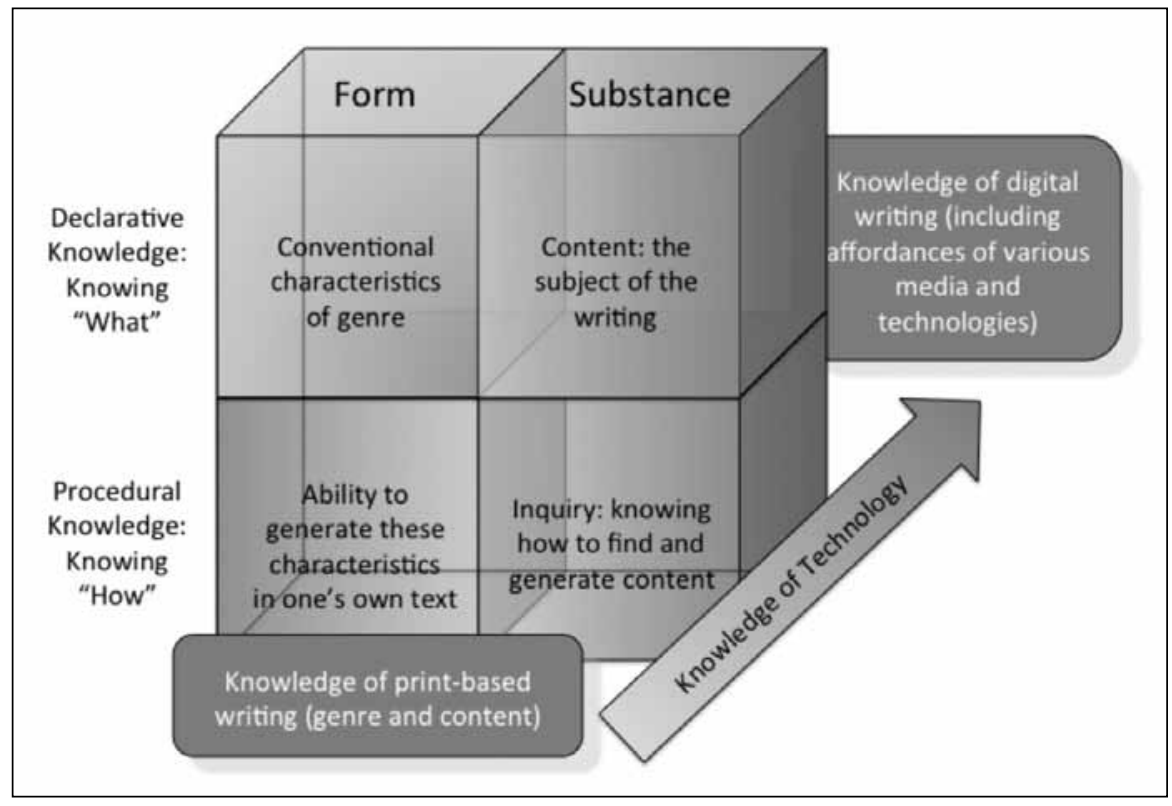

Fig. 4: A model for declarative, procedural, and technological knowledge in digital writing

To successfully create a digital story, Jodi (like all digital writers) needed to understand how to find and incorporate images, music, and other effects to illuminate her story. She could not complete the task without knowing what technologies to use, how to manipulate them, or in what ways these technologies helped 
her to develop both the form and the substance of her story. In our efforts to layer in technological knowledge, to deepen teachers' experiences as writers themselves, we need to help them understand:

- Declarative and procedural knowledge of form, in light of understanding the similarities and differences between a traditional print-based narrative to a digital story

- Declarative and procedural knowledge of substance, in light of using specific affordances of the technology effectively to draw her readers into the digital story

It is with this understanding of the digital writing process in mind that we now bring Jodi's voice into this conversation, hearing more about her thinking as she composed and revised her digital story.

\section{Reimaging the Writing Process}

In order to elaborate the dimensions in this cube, we recommend first reading the personal narrative essay and This I Believe essay about her experience, then viewing Jodi's Digital Story ${ }^{1}$ before reading her reflection on the process of creating this piece.

\section{Jodi's reflections on composing a digital story.}

I know about stories. I know that when adults read to children, we ask them questions about the moral of the story, the emotions of the main characters, or the plot. In my early childhood development courses, I learned that these questions help children to experience a story, rather than just read it. Knowing that readers can identify with narrators and experience stories helped me envision the digital story that I wanted to create. Not only did I want to fulfill the requirements that Troy set in place for the assignment, I also had other goals. I wanted friends, family, and potential employers to see my personal development within the Alternative Breaks program. But I didn't just want my audience to hear me speaking about my life as I narrated the pictures I had collected during my four years in the program. I wanted my readers to feel as though they were experiencing my story with me. 
In order to reach this goal I had to carefully structure my story, and I decided to ask Troy to meet with me for a writing conference outside of class. We met on a Friday morning, and began to think and plan together. I knew that stories contain a beginning, middle, and an end; however, I also understood that authors sometimes pick a point near the end of the story and then flashback to the beginning, allowing the reader to see the growth of the main character. I thought that a flashback might work well for my digital story. Starting at the end and flashing back, I hoped to show my viewers how much the Alternative Breaks program has helped me grow into the person I am today. I wanted to share that I have not always had the privileges I've been blessed with through the Alternative Breaks program, but that service has challenged me to be a better person. I decided that I could best tell this story through three different leadership experiences-being a participant, a site leader, and then a board member. Each of these topics had their own stories within them that would give life and meaning to the bigger picture of my writing. Troy listened to me talk, and he took notes about my ideas and we worked together to create this timeline (Figure 5):

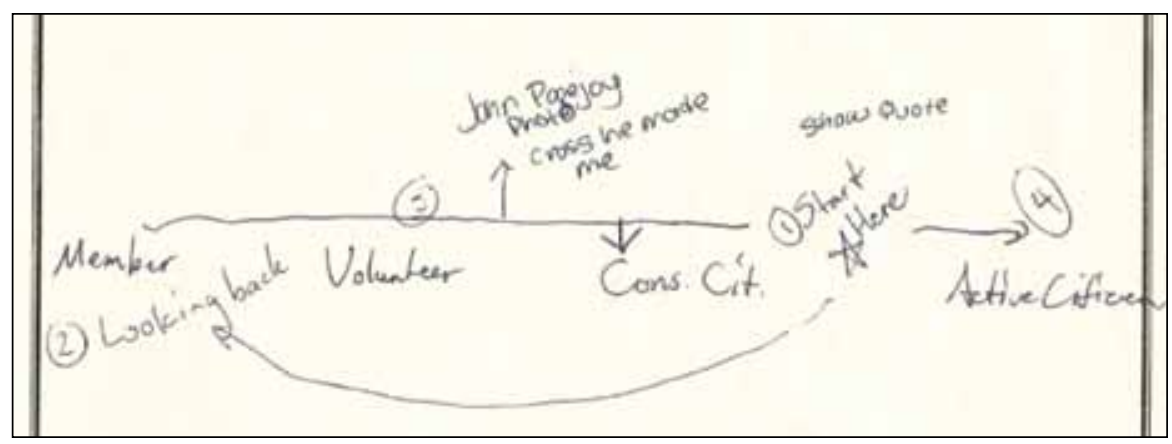

Fig. 5: Notes from Jodi's conference with Troy about her digital story timeline

Once I knew the content of my digital story, I had to tackle the task of constructing the video. I had experience creating a digital presentation that required me to choose a topic, pick a song, input pictures related to the topic, and post the video to YouTube. However, that assignment didn't need to tell a story. I wasn't sure how to take my knowledge of technology from that other task and apply it to creating a digital story that would come full circle. After watching the sample that Troy shared with us, I began to see how transitions and other effects could help reach my goal. 
My "This I Believe" essay was already written, so I revisited it. I realized that I had felt constrained by the formatting of a typical essay and that I had struggled to write the paper about a broad topic like social change. I realized I needed to shift to writing about my journey through service-learning, and I knew the digital story could help me better connect with my audience by showing my personal experience with Alternate Breaks. As I tried to move from the written essay to the digital story, I thought PowerPoint would be a tool to help me. I copied pieces of my "This I Believe" essay into my PowerPoint document. I could see the slides on the right-hand side of the screen, make notes at the bottom of the page, and print out the slides to staple them together and have a paperback copy of my story. Making the story a book first helped bring to life the plot of my digital story-which ultimately became a personal and reflective story on a big chapter in my life.

After the story was sequenced, I recorded the narration one slide at a time. I closed my eyes and really listened to what I was saying, allowing myself to form a mental image of the story. I used these mental images to write notes on each PowerPoint slide about what I saw happening in the scene. Once this was done for all slides, I looked for pictures stored on my laptop, searched old albums on Facebook, and reached out to a few friends who had some photos, so I could begin adding visual images to my words.

From there, it was time to take all the pieces of the puzzle and put them together. Going slide by slide and recording my voice one slide at a time better allowed me to map out the timings of each photo and to put a transition in the middle so that things felt as if they were an integral whole. Instead of selecting pictures and quotes that were memorable moments from my break, I really made an effort to select photos and quotes that encompassed my experiences that would give my viewers a more meaningful experience. My peers had recommended that I take the line of "For this, I believe in social change" from my "This I Believe" essay and use that at the end of my digital story. Because my "This I Believe" essay was strictly text, my words couldn't convey the meaning I wanted them to. Revamping it, adding photos, and actually giving the words I was saying a voice was the biggest component in making that statement a reality.

I aligned my narration with the pictures in iMovie, yet there was still something that was missing. I didn't feel that the sub-stories fit well into the story as a whole. I decided to give each chapter a page turn and each sub-story 
a different transition (fade to black, pixelate, or a blur) to see if that make it more powerful. The transitions gave my digital story more depth. Whenever there was a page turn, it was symbolic of a new chapter occurring; whereas the photos that faded to black were meant to show that the small sub-story was ending and a new one was going to come. I used pixelations at the beginning and the end to create a mirage that allowed me to transition quickly into a flashback or flash forward moment. The transitions made all the difference, and everything fit together to make the story an integral whole that I am proud to share with family, friends, and peers in the Alternative Break program.

\section{Jodi's Knowledge as a Digital Writer}

We can summarize Jodi's declarative knowledge of form and substance, in this case of digital storytelling, quite simply: Jodi brought her extensive knowledge of how stories work to this process of digital storytelling, and she knew that the genre of digital story would allow her to connect with an audience by helping them "experience" her story. Particularly after Troy shared a model, she knew what a digital story looked like and that she could adapt her "This I Believe" essay in terms of content. In short, she understood the craft of story, in the broadest sense, and saw possibilities with digital storytelling.

Procedural knowledge, however, became more complicated, both in terms of form and substance for digital writing. She needed to develop her technological knowledge in order to create the form itself, and she needed to understand how to use technology to generate the content of the digital story. In some cases, the line between form and content blurred. For example, in the personal narrative, Jodi was able to develop her ideas about social change through the use of quotations and description. In the digital story, she had other options. She could deepen her exploration of social change through the use of her own images, effective transitions, appropriate music, and literally bringing in her voice through narration. To accomplish these goals as a writer, Jodi needed to understand how to use the technology to craft an effective, emotionally rich story (procedural). The use of these tools of technology was not just a matter of form, however. Since Jodi's story advanced via photos, accessing appropriate images became as much a matter of content as it was the form of the story. In fact, when she realized that she could not find adequate images on her computer, she downloaded them from Facebook and asked friends to send them to her. These methods of inquiry required technological knowledge beyond the movie making program, requiring specific communication with others that enabled both the form and the substance of the piece. 
To use Porter's terms, Jodi's story was "illuminating" throughout, from beginning to end. Her process led her to develop knowledge of digital storytelling in all four quadrants of declarative and procedural knowledge, yet it was her knowledge of technology (both declarative and procedural) that enabled the production of the writing. The end result deepened her knowledge of writing - and her understanding of herself as a writer. This type of learning needs to happen for students as they continue to grow and change as writers in a digital world.

\section{Conclusions}

Jodi reflected on her experience:

The process of writing a digital story has affected me as a writer in more ways than I could have ever dreamed. Through this, I see a different part of myself as a writer and as a reflector. We, as humans, have busy lives and are always going about our day-to-day tasks that can seem stressful and monotonous. Writing this story helped me take a step back and see everything that I have accomplished as a person. It allowed me to see where I used to be and just how far I have come. Every time I watch the video I identify with a different emotion and a different perspective on the story. As a writer, I have been able to see my process of writing and how I can use my words to create a powerful message. I've had the ability to move and educate groups of people that are familiar and unfamiliar with Alternative Breaks. Now, when I walk into an interview and they ask me about any ideas I have on incorporating technology in the classroom, what are Alternative Breaks, or even who I am as a writer, I have confidence knowing that I can answer their questions not by telling them, but by showing them.

One of the most interesting elements of composing a digital story is the recursive nature of moving back and forth between print text and video. Some students report that they write out the full script, whereas others organize all the pictures first. Most use some combination of the two, recursively moving back and forth between traditional alphabetic literacy and multimodal literacy. For Jodi, brainstorming began many weeks before in her personal narrative and "This I Believe" essay, and then on paper when working with Troy to develop the timeline. The most interesting part about the brainstorming was that, even as she described her experiences in the Alternative Break program in a chronological order, Troy began to hear patterns 
to how she described the changes in herself and these changes did not follow the chronology. Through their conference, they developed a story structure that met her writing goals. Jodi discovered that the genre of digital story opened opportunities for her as a writer.

As teacher educators and teachers continue to reimagine the writing process with many forms of digital writing, specifically with digital storytelling, we can learn much from Hillocks (1995) and Smith and Wilhelm's (2006) work. Pushing the boundaries of declarative and procedural knowledge of both substance and form to include the affordances of newer technologies allows us to build on theoretically sound interpretations of writing as we justify decisions in curriculum, instruction, and assessment.

Though we feel the need to go deeper into writing and to complicate our knowledge by assigning digital genres is self-evident in Jodi's story, we also consider the importance of developing what Mishra and Koehler describe as "Technological Pedagogical Content Knowledge" in teachers of writing. Specifically, one element of that framework, "technological content knowledge" could be useful as we continue to explore the types of knowledge that teachers need to have in order to succeed in teaching digital writing:

Accordingly, Technological Content Knowledge (TC or TCK) is an understanding of the manner in which technology and content influence and constrain one another. Teachers need to master more than the subject matter they teach, they must also have a deep understanding of the manner in which the subject matter (or the kinds of representations that can be constructed) can be changed by the application of technology. Teachers need to understand which specific technologies are best suited for addressing subject-matter learning in their domains and how the content dictates or perhaps even changes the technology-or vice versa. (Mishra \& Koehler, 2008, p. 9)

In moving the two-dimensional table of declarative and procedural knowledge into a three-dimensional cube that recognizes the effects and importance of technology, we appreciate how the "kinds of representations that can be constructed" are transformed as we move from print to digital text. In fact, we believe that the intersections of technology and knowledge of substance and form represented in this cube indicate that content knowledge for teachers of writing subsumes technological knowledge. In the digital era in which we live, technology cannot be 
divorced from a writer's understanding of craft and substance. It is within the intersection that Jodi reimagined herself as a writer, and it is within the intersection that we, as teachers of writing, reimagine what it means to teach writing.

\section{Note}

1. See http://youtu.be/krKHBliwIF0

\section{References}

Hicks, T. (2009). The digital writing workshop. Portsmouth, $\mathrm{NH}$ : Heinemann.

Hillocks, G. (1995). Teaching writing as reflective practice. Teachers College Press.

Lieberman, A., \& Wood, D. (2003). Inside the national writing project: Connecting network learning and classroom teaching. Teachers College Press.

Mishra, P., \& Koehler, M. J. (2008). Introducing technological pedagogical content knowledge. In Annual Meeting of the American Educational Research Association (New York, New York) (pp. 1-16). Retrieved from http://www.msuedtechsandbox. com/2010RouenY2/Readings/wk1d2 mishra\&koehler.pdf
National Writing Project, DeVoss, D., EidmanAadahl, E., \& Hicks, T. (2010). Because digital writing matters: Improving student writing in online and multimedia environments. San Francisco: Jossey-Bass.

National Writing Project, \& Nagin, C. (2006). Because writing matters: Improving student writing in our schools (Rev Upd.). Jossey-Bass.

Porter, B. (n.d.). About digital storytelling. Retrieved from http://digitales.us/about/ digital-storytelling

Smith, M., \& Wilhelm, J. D. (2006). Going with the flow: How to engage boys (and girls) in their literacy learning (1st ed.). Heinemann. 


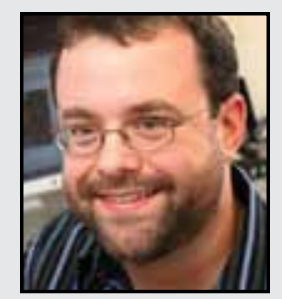

Troy Hicks is an Associate Professor of English at Central Michigan University and focuses his work on the teaching of writing, literacy, and technology, and teacher education and professional development. A former middle school teacher, he collaborates with $\mathrm{K}-12$ colleagues and explores how they implement newer literacies in their classrooms. Hicks directs CMU's Chippewa River Writing Project, a site of the National Writing Project, and frequently conducts professional development workshops related to writing and technology. He is author of the Heinemann titles, Crafting Digital Writing (2013) and The Digital Writing Workshop (2009) as well as a co-author of Because Digital Writing Matters (Jossey-Bass, 2010).

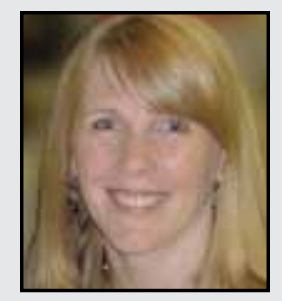

Kristen Turner is an Assistant Professor in the Fordham Graduate School of Education. A former high school English and social studies teacher, Turner works with in-service and preservice teachers across content areas to build students' literacy skills. Her research focuses on the teaching of writing and the effects of technology on written composition. She is a Teacher Consultant for the National Writing Project and director of the Digital Literacies Collaborative at Fordham University.

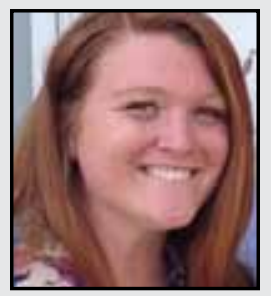

Jodi Stratton is pursuing her undergraduate degree in Elementary Education and Child Development with minors in Language Arts and Integrated Science at Central Michigan University. She has high hopes of becoming an early childhood educator that will successfully incorporate service learning and new technology practices in her classroom. Jodi serves on the advisory board as a Site Leader Orientation and Training Co-Chair for Central Michigan University's Alternative Breaks Program and also is an active e-board member for the honorary teaching fraternity, Kappa Delta Epsilon. 